Full Length Article

\title{
Cost-savings accruable to removing value added tax from antiretrovirals in the South African private health sector
}

\author{
Varsha Bangalee*, Fatima Suleman ${ }^{1}$ \\ Discipline of Pharmaceutical Sciences, School of Health Sciences, University of KwaZulu-Natal - Westville Campus, \\ Private Bag X54001, Durban, 4000, KZN, South Africa
}

\section{A R T I C L E I N F O}

Article history:

Received 19 February 2016

Accepted 7 November 2016

Keywords:

Essential medicines

Value added tax removal

Antiretrovirals

\begin{abstract}
A B S T R A C T
Background: Despite the important and essential role that medicines play in any society, all medicines, including those identified as essential, are uniformly subjected to $14 \%$ value added tax (VAT), regardless of their therapeutic value in the private healthcare sector of South Africa. The aim of this article is to demonstrate the potential cost-saving attained from the removal of VAT from the private sector pricing of essential medicines, using antiretroviral treatment as an example.

Methods: An empirical analysis was undertaken to illustrate the potential cost-saving achieved by removing VAT from the Single Exit Price and the dispensing fee of essential medicines. This outcome was demonstrated by applying the methodology to an adult fixed dose combination 1st line antiretroviral regimen as well as to a group of 3rd line antiretroviral medicines.

Results: The potential saving for the lowest priced generic and originator 1st line antiviral regimen accrued to ZAR 693.84 and ZAR 1085.04 over a year respectively. Regarding the 3rd line antiretroviral drugs, results yielded an annual saving of ZAR 1678.68 (darunavir), ZAR 5741.04 (maraviroc) and ZAR 159.48 (rilpivirine).

Conclusions: Lobbying for the removal of VAT from the supply chain of medicines should be intensified. Policy development to monitor and recover lost government revenue through the removal of taxes should be explored.

Copyright $\odot$ 2016, The Authors. Production and hosting by Elsevier B.V. on behalf of Johannesburg University. This is an open access article under the CC BY-NC-ND license

(http://creativecommons.org/licenses/by-nc-nd/4.0/).
\end{abstract}

\footnotetext{
* Corresponding author. Fax: +27 312607792.

E-mail addresses: bangalee@ukzn.ac.za (V. Bangalee), sulemanf@ukzn.ac.za (F. Suleman). Peer review under responsibility of Johannesburg University.

${ }^{1}$ Fax: +27 312607792 . 


\section{Introduction}

As a middle-income country, South Africa faces similar healthcare challenges to other developing countries (Bulla et al., 2014; Coovadia, Jewkes, Barron, Sanders, \& McIntyre, 2009). The country's residents are faced with a high disease burden, due largely to the HIV/AIDS pandemic, as well as to lack of essential healthcare resources and high medicine costs, which affect the availability, accessibility and affordability of essential medicines for a large percentage of the population (Cameron, Ewen, Ross-Degnan, Ball, \& Laing, 2009; Gray \& Matsebula, 2000).

Essential medicines can be defined as those that satisfy the priority health care needs of the population, being identified with careful consideration of disease prevalence, evidence of medicine efficacy and safety, and comparative costeffectiveness (Department of Health, 2012). Furthermore, to improve service delivery and outcomes of the healthcare system, these medicines should be available at all times, in adequate quantities, in the appropriate dosage forms, with assured quality and adequate information, and at a price that individuals and communities can afford (Department of Health, 2012).

Medicine prices in the South African private sector are governed by the Single Exit Price (SEP) legislation. The SEP consists of the ex-manufacturer's price, this being the largest segment, a logistics fee of $10 \%-15 \%$, this often being higher for essential medicines, and the standard $14 \%$ value added tax (VAT) (Ball, 2011; Bangalee \& Suleman, 2015; Republic of South Africa, 1997). Dispensers are remunerated for their services through the additional charge of a dispensing fee, which is calculated on a legislated tiered framework contingent on the SEP of the medicine, and which also includes an additional VAT component.

The primary rationale for imposing taxes on society is the need for government to finance public expenditure (National Treasury, 2007). A well-designed and progressive tax system can promote both economic growth and social justice (Creese, 2011). Since its inception in 1991, VAT remains the second most important source of government revenue in South Africa, but as in most countries, its impact on income distribution is controversial (Jansen, Stoltz, \& Yu, 2012).

During the early initiation of VAT in South Africa, it was maintained that its application without any exemptions was regressive. This, coupled with South Africa's previous political history and extremely skewed distribution of wealth, warranted an intervention that would protect public interest, in particular the poor. This led to the concessionary VAT treatment of a number of merit goods, such as certain food items, that are classified as essential foodstuff (Jansen et al., 2012). In order to attain merit goods status, one of the traits is that a commodity needs to be in the public interest as well as essential. Despite the important and essential role that medicines play in any society, all medicines, including those identified as essential, are uniformly subjected to $14 \% \mathrm{VAT}$, regardless of their therapeutic value. In addition, all essential medicines are taxed equally to cosmetic products, as well as other unregulated and items of unproven efficacy that are sold in pharmacies (Bate, Tren, \& Urbach, 2006).
VAT on medicines ranges from zero in Brunei to $19 \%$ in Peru (The African Executive, 2005). A study conducted by Bate et al. (2006) identified a uniform relationship between tariffs and access to essential medicines, whereby increases in tariffs produced a corresponding decrease in essential medicine access and vice versa. As the economic viability and growth of any nation also depends on the health of its population, the removal of taxes on essential medicines is justified, as increased access to medicines would improve overall health and wellbeing.

In South Africa, many parties argue that VAT only operates in the private sector, and hence should not affect people accessing health care through the public sector. However, this ignores the fact that many users of the public health system purchase medicines from private pharmacies. With approximately only $16 \%$ of the South African population having access to medical insurance (OECD, 2011), the remaining $84 \%$ rely on the public sector, and make out-of-pocket purchases in the private sector due to medicine shortages in the public sector and to an inability to access public hospitals and clinics due to distance, time and cost constraints (Bate et al., 2006). Additionally the concerns about poor quality of services offered by public sector has also been shown to be a major barrier to access and has created a preference by the public for services in the private sector, which is largely funded out-ofpocket (Department of Health, 2011). Research has also shown that despite essential medicines being freely available in the public sector, the ease of access, privacy, confidentiality and short queues, generally attract patients, especially with sexually transmitted infections to seek treatment in the private sector (Chabikuli, Schneider, Blaauw, Zwi, \& Brugha, 2002; Schneider, Blaaw, Dartnall, Coetzee, \& Ballard, 2001). Equity in healthcare for all South African residents was an important key element during the development of the $\mathrm{Na}$ tional Drug Policy (NDP), and implementing the Essential Medicines List (EML) was an important part of achieving the policy's objectives. Within this context, the EML should not operate solely in the public sector, but also serve the better interests of the population who use private sector health care services.

There has been much debate about the impact of removing VAT on the accessibility of essential medicines (The African Executive, 2005) in developing countries. In Nigeria, only $10 \%$ of the population have access to essential medicines, with taxes and tariffs on imports, including essential medicines, totalling $28 \%$. In Brazil, $40 \%$ of the population have access to essential medicines through the public health sector, with a combined tax and tariff burden of 29\% (Bate et al., 2006). Similar figures are evident in other developing countries, where high tariffs and taxes reduce the accessibility of medicines to the poorest members of the population, and exacerbate their poor health outcomes (The African Executive, 2005).

The aim of this paper is to explore the possible savings accrued from removing VAT from the private sector pricing of essential medicines, using antiretroviral treatment as an example. South Africa has the highest prevalence of HIV/AIDS in the world, with a reported 2.4-million people being infected in 2012, which is 1.2-million more than in 2008 (Malan, 2014). While several strides have been taken towards making 
antiretroviral (ARV) therapy more affordable in South Africa, various issues still need to be addressed to ensure that it is accessible for all those afflicted with the disease. Many antiretroviral medicines, including the medicines used to treat people failing on 2nd line antiretroviral therapy, are not adequately provided in the public sector (Fix the patent laws, 2012). Often, despite good adherence, individuals experience treatment failure on 1st and 2nd line antiretroviral therapy, and require treatment with 3rd line medicines, which are only available through private clinics or specific non-government organisations, such as Doctors without Borders. Furthermore, these medicines are considerably more expensive than the 1st and 2nd line options, as they are under patent protection, with no generic options being available. In addition, high medicine prices are also a result of the weak South African Rand, as most ARVs are imported, with the foreign currency exchange rate contributing to the trend of increasing medicine prices, despite instituting government price reducing polices.

The findings discussed in this study may not be novel, nor do they do justice to the intricacy of issues related to taxes on essential medicines, yet they occupy the focus of several political debates in recent years (International Federation of Pharmaceutical Manufacturers \& Associations, 2012). This is due to the fact that current VAT policies contribute to the decreased accessibility of essential medicines to the poorest of the poor (Cameron et al., 2009), which is counter-active to the objectives of the NDP (Department of Health, 1996). Notably, any savings in the private sector, will contribute to reducing the burden of patients accessing the public sector, hence improving delivery of care. Furthermore, this study hopes to add to the current body of literature directed at reducing ARV treatment costs in the private sector, considering that many patients transition between the public and private health sectors for their treatment (Southern African HIV Clinicians Society, 2014).

\section{Method}

The research consisted of an empirical analysis to illustrate the potential cost-saving achieved by removing VAT from the SEP and the dispensing fee of essential medicines. This outcome was demonstrated by applying the methodology to an adult fixed dose combination (FDC) 1st line antiretroviral regimen, as described by the 2013 South African Standard Treatment Guidelines and Essential Medicines List, as well as to a group of 3rd line ARV medicines available in South Africa. The FDC tablet consists of $300 \mathrm{mg}$ tenofovir (TDF), $200 \mathrm{mg}$ emtricitabine (FTC) and $600 \mathrm{mg}$ efavirenz (EFV). Darunavir $600 \mathrm{mg}$, maraviroc $150 \mathrm{mg}$ and rilpivirine $25 \mathrm{mg}$ tablets, represent the second data set, which were the only 3rd line ARV medicines for which pricing data was available.

ARV therapy was considered a suitable sample for various reasons: treatment regimens are relatively standard across developing countries and the large impact that the condition has had on the South African population (WHO, 2010; Coovadia et al., 2009). Furthermore, the stigma attached to the disease has often resulted in many individuals avoiding public health facilities and seeking treatment in private medical settings (Famoroti, Fernandes, \& Chima, 2013). Finally, the chronic nature of the disease justifies its selection, as ongoing treatment contributes to lifelong expenditure. While these results may not be generalizable to all essential medicines, they provide valuable insight into the improved affordability of medicines with VAT removed.

Private sector prices (SEP's) for the originator and the lowest priced generic for each of the sample medicines as at 10 November 2015 were retrieved from the South African Medicine Price Registry, 2010. The SEP consists of the exmanufacturers price, logistics fee and a VAT of $14 \%$, which is calculated from the sum of the two costs and added to them. The maximum dispensing fee, VAT inclusive, was calculated for each medicine, as per the price bands outlined in the amendments to the Medicines and Related Substances Act (Republic of South Africa, 2015).

The Medicines and Related Substances Act allows for the following charges (excl. VAT) additional to SEP:

- Where the SEP is less than ZAR 85.69, the maximum dispensing fee is ZAR $7.04+46 \%$ of the SEP.

- Where the SEP is less than ZAR 799.99 but more than ZAR 228.56 , the maximum dispensing fee is ZAR $59.83+15 \%$ of the SEP.

- Where the SEP is greater than or equal to ZAR 799.99, the maximum dispensing fee is ZAR $140.00+5 \%$ of the SEP.

Two costs were calculated, the first (Table 1), where the VAT costs were included on the initial costs as well as the dispensing fee, and the second (Table 2) where all VAT costs are excluded. The cost-saving per regimen was determined by comparing medicine prices excluding VAT to those that would be expected with VAT charged in the supply chain.

\section{Results}

Tables 1 and 2 illustrate the final price of surveyed medicines, VAT inclusive and exclusive respectively. As indicated in Table 2, the potential saving for the lowest priced generic ARV was ZAR 57.82, and ZAR 90.42 per month for the originator medicines, which accrues to a saving of ZAR 693.84 and ZAR 1085.04 over a year respectively. Removing VAT for the $3 \mathrm{rd}$ line ARV drugs, for which there are no generics available, resulted in an annual saving of ZAR 1678.68 (darunavir), ZAR 5741.04 (maraviroc) and ZAR 159.48 (rilpivirine).

The annual savings illustrate the potential savings accrued as a result of VAT removal from the pharmaceutical supply chain for all samples included in the analysis.

\section{Discussion}

Taxation is essential for governments to achieve their mandates, as the amount of tax obtained determines the services that can be provided (Creese, 2011). These are obtained in various ways, but since its inception, the mandated $14 \%$ VAT rate has faced strong opposition from several lobbyists in South Africa, due to concerns surrounding the 
Table 1 - Final price for adult fixed dose combination 1st line antiretroviral regimen and 3rd line regimens (VAT inclusive).

\begin{tabular}{|c|c|c|c|c|c|}
\hline \multirow[t]{2}{*}{ Fee components } & \multicolumn{2}{|c|}{ 1st line FDC ARV regimen } & \multicolumn{3}{|c|}{ 3rd line ARV regimen } \\
\hline & $\begin{array}{l}\text { Lowest priced } \\
\text { generic ( } 30 \text { tabs) }\end{array}$ & $\begin{array}{l}\text { Originator } \\
\text { (30 tabs) }\end{array}$ & $\begin{array}{l}\text { Darunavir } 600 \mathrm{mg} \\
\quad \operatorname{tab}(60 \text { tabs })\end{array}$ & $\begin{array}{l}\text { Maraviroc } 150 \mathrm{mg} \\
\quad \operatorname{tab}(60 \text { tabs })\end{array}$ & $\begin{array}{l}\text { Rilpivirine } 25 \mathrm{mg} \\
\text { tab (30 tabs) }\end{array}$ \\
\hline Ex-manufacturers price (A) & 235.57 & 385.78 & 634.61 & 2792.93 & 38.51 \\
\hline Logistics fee (B) & 31,80 & 57.87 & 95.19 & 167.57 & 5.78 \\
\hline$A+B$ & 267.36 & 443.65 & 729,8 & 2960,5 & 44,29 \\
\hline $14 \% \mathrm{VAT}$ & 37.43 & 62.11 & 102.17 & 414.47 & 6.19 \\
\hline$=\mathrm{SEP}$ (VAT incl.) & 304.8 & 505.76 & 831.97 & 3374.97 & 50.48 \\
\hline $\begin{array}{l}\text { Dispensing fee (calculated } \\
\text { on SEP, VAT incl.) }\end{array}$ & 105.55 & 135.69 & 181.59 & 308.75 & 30.26 \\
\hline $14 \% \mathrm{VAT}$ & 14.77 & 19 & 25.43 & 43.22 & 4.23 \\
\hline Dispensing fee $+14 \%$ VAT & 120.32 & 154.69 & 207.02 & 351.97 & 34.49 \\
\hline $\begin{aligned}= & \text { Final price (SEP, VAT incl. } \\
& + \text { Dispensing fee, VAT incl.) }\end{aligned}$ & 425.13 & 660.45 & 1038.99 & 3726.5 & 84.98 \\
\hline
\end{tabular}

Notes: All prices are in ZAR.

Table 2 - Final price for adult fixed dose combination 1st line antiretroviral regimen and 3rd line regimens (VAT exclusive).

\begin{tabular}{|c|c|c|c|c|c|}
\hline \multirow[t]{2}{*}{ Fee components } & \multicolumn{2}{|c|}{ 1st line FDC ARV regimen } & \multicolumn{3}{|c|}{ 3rd line ARV regimen } \\
\hline & $\begin{array}{l}\text { Lowest priced } \\
\text { generic (30 tabs) }\end{array}$ & $\begin{array}{l}\text { Originator } \\
\text { (30 tabs) }\end{array}$ & $\begin{array}{l}\text { Darunavir } 600 \mathrm{mg} \\
\quad \text { tab (60 tabs) }\end{array}$ & $\begin{array}{l}\text { Maraviroc } 150 \mathrm{mg} \\
\text { tab (60 tabs) }\end{array}$ & $\begin{array}{l}\text { Rilpivirine } 25 \mathrm{mg} \\
\text { tab (30 tabs) }\end{array}$ \\
\hline Ex-manufacturers price & 235.57 & 385.78 & 634.61 & 2792.93 & 38.51 \\
\hline Logistics fee & 31,80 & 57.87 & 95.19 & 167.57 & 5.78 \\
\hline SEP (VAT excl.) & 267.36 & 443.65 & 729,8 & 2960,5 & 44,29 \\
\hline Dispensing fee & 99.94 & 135.69 & 181.59 & 308.75 & 30.26 \\
\hline $\begin{array}{l}=\text { Final price (SEP, VAT } \\
\text { excl. + Dispensing fee, } \\
\text { VAT excl.) }\end{array}$ & 367.30 & 154.69 & 207.02 & 351.97 & 34.49 \\
\hline Total script saving & 57.82 & 90.42 & 139.89 & 478.42 & 13.29 \\
\hline Annual saving & 693.84 & 1085.04 & 1678.68 & 5741.04 & 159.48 \\
\hline
\end{tabular}

Notes: All prices are in ZAR.

regressive effect it would have on the country's poorest households.

Unlike other developing countries, such as India, where import duties are imposed to protect the local pharmaceutical industry, South Africa has greatly reduced the tariffs applied to pharmaceuticals entering the country. Despite this effort however, South Africa still faces high medicine prices, owing to mark-ups encountered in the supply chain, one of these notably being VAT. Although South Africa may not have the highest sales taxes when compared to other developing countries, it should be emphasized that any effort to reduce medicine prices should be considered, particularly in light of the high cost of originator medicines, hence the option of removing VAT from the supply chain should be explored.

A study was conducted by Bate et al., in 2005 using private sector pricing data to demonstrate the effect that VAT has on the pricing of ARV's in South Africa. It calculated the potential savings based on one month's supply of antiretroviral triple therapy consisting of Combivir (lamivudine and zidovudine) and nevirapine, which were the 1st line regimen at the time. The findings revealed that the typical monthly cost of antiretroviral treatment was ZAR 586, of which ZAR 72 went directly to government in the form of VAT (Bate et al., 2006). The authors declared that this ZAR 72 could have been better spent purchasing essential food items to sustain the health of the individual. Similarly, the savings depicted in the current study may also be better utilized towards improving patients' quality of life, particularly as the survival outcomes of individuals living with HIV/AIDS on antiretroviral drugs is further improved by an adequate nutritional diet.

Although not the main focus of this article, it is interesting to look at the price differentials between medicines deemed essential in the public sector to its price in the private sector. Since the Bate et al. study, South Africa has made significant improvements in antiretroviral therapy, including adopting a fixed dose combination treatment that government negotiated at a cost of ZAR 89.37 per month, which represents a significant saving compared to the old single drug tenders (Southern African HIV Clinicians Society, 2013). A comparison of the current negotiated government tender price (ZAR 89.39), the private sector prices lowest priced generic (ZAR 304.8) and originator price (ZAR 505.76) for the 1st line FDC ARV regimen demonstrate the considerable price differences between the two sectors. This further highlights the inefficiencies in obtaining the most competitive prices for life saving medicines in the private sector. It is important to note that very few HIV positive patients are solely on one type of treatment. The nature of the disease often warrants individuals to be on a plethora of treatment combinations, depending on the complications and opportunistic infections 
that arise during their lifespan, which further increases treatment costs.

With regard to how the cost implication of medicines affects accessibility and adherence, systematic research globally demonstrates an inverse relationship between medicine prices and medicine usage. Studies conducted in the USA revealed that a $10 \%$ increase in patient prices of prescription medicines resulted in a 2-6\% drop in medicine use (Creese, 2011). The outcome of this being lower rates of treatment, poorer compliance and increased treatment discontinuation. Similar medicine deterring effects linked to increased medicine prices were observed in the UK (Creese, 2011). High income countries show great variation with regard to fiscal policies in relation to medicine pricing (Creese, 2011). These policies vary from certain countries such as Australia, Japan, and Korea, which do not impose any tax on medicines, to policies that vary the tax according to the prescription status of the medicine for example Sweden, which exempts prescribed medicines only (Creese, 2011). Analysis conducted by the South African National Treasury in 2006, on both prescription and nonprescription medicines reveal that the VAT incidence is currently shared in the ratio of $60 \%-40 \%$ between the supply chain and consumers respectively. This indicates that consumers are likely to enjoy $40 \%$ or less of any 'savings' facilitated by adopting a more favourable VAT dispensation (National Treasury, 2007). A major concern in South Africa is the differential treatment of medicine pricing and status (i.e. essential medicine status) in the public and private sectors, as VAT only operates in the private sector. This may however change, with the introduction of universal health coverage in South Africa, where the EML may not operate solely in the current public sector, but be included under NHI funded plans; where there will be a unified set of treatment guidelines and clinical pathways.

The option of adopting a more favourable tax system in South Africa for EML's requires decision-makers to be attentive to the experiences of other developing countries that have made advances in removing or reducing their taxes on medicines. These include Kyrgyzstan, where VAT and regional sales tax on medicines were both reduced in 2004, and Pakistan, which also removed the $15 \%$ sales tax on medicines (Creese, 2011). However, there has been little data in both countries to support how lower taxes has resulted in improved prices and accessibility to medicines. Some insight can be gained from Peru, where sales tax and VAT were removed for a range of cancer and antiretroviral medicines in 2001, but little change in retail prices was observed (Creese, 2011). It was postulated that this was due to the lack of supporting regulations to safe guard the policies from being manipulated by the market to counter the effect of reduced taxes by increasing the mark ups elsewhere in the supply chain. It is therefore imperative for the South African government to be vigilant and pre-emptive of these outcomes, to ensure that policies can be instituted to safeguard against these influences.

The development of rational medicines use guides, with EML's are ranked high in the WHO proposal for improving access to medicines in low-income countries. South Africa has successfully responded to this by instituting, monitoring and updating its STGs thereby ensuring an appropriate selection of cost-effective treatments suitable for the country's disease profile (Department of Health, 2012). Where government falls short however, is in acknowledging that these guidelines and lists should also be introduced into the private sector. This is particularly pertinent as healthcare delivery in South Africa is characterised by a large private sector operating alongside a public health sector. This duality beckons for better cohesion between the Standard Operation Procedures and regulatory policies that exist between the two sectors.

It is easy to understand governments' firm resistance to removing VAT on medicines, as this would constitute a considerable loss in government revenue. However, the expected benefits to quality of life and life expectancy linked to improved accessibility to medicines far out-weigh the apprehension experienced by policy makers (Creese, 2011). In addition, removing VAT on selective medicines, such as essential medicine, would in part cushion this loss. South African studies conducted by Fourie and Owen in 1993, which explored the effect of zero-rating of merit food items, concluded that zero-rating significantly reduced the taxburden on the lower-income households. Perhaps an alternate policy to zero-rating of essential medicines would include a reduction of VAT rather than its complete removal, thus ensuring that some revenue is still recouped to invest in other progressive government priorities. Many countries use a lower VAT rate on medicines than the standard VAT rate, however this is most often observed in high-income countries for example Greece, Austria, Italy, Finland, Switzerland and Turkey (Creese, 2011).

There is a scarcity of information on the practice of medicine taxation. Some countries, in the best interest of the public, imposed or increased taxes on health-damaging consumption items and behaviour (Creese, 2011). The argument for this stems from the fact that tax policies should function not only to promote public health objectives, but also simultaneously discourage activities that are counteractive or harm a countries human capital. The revenue raised through increased taxes on unhealthy consumption patterns and behaviour can, in this instance, compensate for losses brought about by eliminating VAT on essential medicines. Health advocates and lobbyists have debated the imposition of 'sin taxes' on tobacco, alcohol and even sugared drinks. The strong link between alcohol, tobacco, unhealthy food, ill health and premature death has long been established. Consumption of these commodities place added demands on healthcare systems, thus imposing costs on all citizens (Creese, 2011), and should therefore be better explored.

\section{Limitations}

The main limitation of the study was calculating the dispensing fee component of the surveyed medicines. In this study, the maximum dispensing fee was applied, but may not represent a true reflection of actual practice, as several pharmacies may vary the fee charged in order to remain competitive. A further limitation of the study is that findings may not be generalizable to all essential medicines as medicine prices are often affected by several factors, including the medicine 
class and the level of competition between manufacturers, amongst others. The study also does not investigate the effect of VAT on access to medicines, however this would be a recommendation for future work.

\section{Conclusion}

It is widely acknowledged that taxes are a necessity for governments to provide the structures and services that allow for a healthy and productive society. In South Africa, like many other developing countries, VAT on medicines represents an important source of revenue. However, the fundamental role that medicines play, in particular essential medicines, which by definition should be available and accessible to all of a country's population cannot be ignored. The findings of this study invite a more in-depth analysis of how best to implement VAT exemptions on essential medicines, as even small changes to the tax treatment, as proposed in this paper, may affect the relative position of the poorest households in South Africa (Bate et al., 2006). In addition, reducing medicine prices would greatly ease dependence of the population on the public health system, and increase direct access to medicines that could arguably control the prevalence of communicable diseases, such as tuberculosis (Hargreaves et al., 2011). Another recommendation stemming from this study would be to determine what percentage of essential medicines is being purchased in the public sector, to ascertain the precise saving that may arise.

Global trends on taxes on medicines should be further explored to design a fiscal policy that will better align these costs with the objectives of the South African NDP. Government should acknowledge that medicines prices should not be treated with a single umbrella policy, as they are not a single commodity, ranging from luxury consumption foods to essential life-saving goods (Creese, 2011), and should rather be controlled selectively by applying VAT concessions on essential medicines exclusively. Finally, monitoring is required to ensure that savings are actually being passed on to consumers, and not distorted by retailers' price increases in the supply chain.

\section{Acknowledgements}

The authors are thankful to Ms Carin Martin, for all her invaluable advice and editorial support.

\section{R E F E R E N C E S}

Ball, D. (2011). The regulation of mark-ups in the pharmaceutical supply chain. WHO/HAI Project on medicine prices and availability, review series on pharmaceutical pricing policies and interventions. Available from: www.haiweb.org/medicineprices/policy/ index.html.

Bangalee, V., \& Suleman, F. (2015). Evaluating the effect of a proposed logistics fee cap on pharmaceuticals in South Africa-A pre and post analysis. BMC Health Serv Res, 15(1), 1.
Bate, R., Tren, R., \& Urbach, J. (2006). Still taxed to death: An analysis of taxes and tariffs on medicines, vaccines and medical devices. Washington, DC: AEI-Brookings Joint Center for Regulatory Studies. Available from: www.aei-brookings.aei.org/admin/ authorpdfs/page.php?id=1136.

Bulla, D., Fall, A. S., Gazdar, H., Krongkaew, M., Lenhardt, A., Mouley, S., et al. (2014). Middle-income countries policy guide. Available from: http://static1.squarespace.com/static/ 539712a6e4b06a6c9b892bc1/t/540ee984e4b02e0dc20ac63d/ 1410263523192/MICs+final_final_09092014.pdf.

Cameron, A., Ewen, M., Ross-Degnan, D., Ball, D., \& Laing, R. (2009). Medicine prices, availability, and affordability in 36 developing and middle-income countries: A secondary analysis. The Lancet, 373(9659), 240-249.

Chabikuli, N., Schneider, H., Blaauw, D., Zwi, A. B., \& Brugha, R. (2002). Quality and equity of private sector care for sexually transmitted diseases in South Africa. Health Policy and Planning, 17(suppl 1), 40-46.

Coovadia, H., Jewkes, R., Barron, P., Sanders, D., \& McIntyre, D. (2009). The health and health system of South Africa: Historical roots of current public health challenges. The Lancet, 374(9692), 817-834.

Creese, A. (2011). WHO/HAI project on medicine prices and availability review series on pharmaceutical pricing policies and interventions. Working paper 5: Sales taxes on medicines. Available from: http://www.haiweb.org/medicineprices/05062011/Taxes\% 20final\%20May2011.pdf.

Department of Health. (1996). National drug policy for South Africa. Pretoria. Available from: http://www.doh.gov.za/docs/policy/ drugsjan1996.pdf.

Department of Health. (2011). National Health Insurance in South Africa: Policy paper. Available from: http://www.bowman.co.za/ FileBrowser/ContentDocuments/NHI.pdf.

Department of Health. (2012). Hospital level adults standard treatment guidelines and essential drugs list. The National Department of Health, 3rd Edition, South Africa. Available from: http://www.kznhealth.gov.za/pharmacy/edladult_2012. pdf http://www.africanexecutive.com/modules/magazine/ articles.php? article $=81$.

Famoroti, T. O., Fernandes, L., \& Chima, S. C. (2013). Stigmatization of people living with HIV/AIDS by healthcare workers at a tertiary hospital in KwaZulu-Natal, South Africa: A cross-sectional descriptive study. BMC Medical Ethics, 14(Suppl 1), S6.

Fix the patent laws. (2012). Twelve years on ARVs. Available from: http://www.fixthepatentlaws.org/?p=144.

Fourie, F., \& Owen, A. (1993). Value-added tax and regressivity in South Africa. S Afr J Econ, 61(4), 308-319.

Gray, A., \& Matsebula, T. (2000). Drug pricing. In South African health review. Durban: Health Systems Trust. Available from: http://www.hst.org.za/sahr/2000/chapter9.htm.

Hargreaves, J. R., Boccia, D., Evans, C. A., Adato, M., Petticrew, M., \& Porter, J. D. H. (2011). The social determinants of tuberculosis: From evidence to action. Am J Public Health, 101(4), 654-662.

International Federation of Pharmaceutical Manufacturers \& Associations. (2012). The changing landscape on access to medicines. Available from: http://www.ifpma.org/fileadmin/ content/Publication/2012/ChangingLandscapes-Web.pdf.

Jansen, A., Stoltz, E., \& Yu, D. (2012). Improving the targeting of zerorated basic foodstuffs under value added tax (VAT) in South Africa An exploratory analysis. Stellenbosch Economic Working Papers: 07/12. Available from: http://www.ekon.sun.ac.za/ wpapers/2012/wp072012/wp-07-2012.pdf.

Malan, M. (2014). SA has highest number of new HIV infections worldwide - Survey. Mail \& Guardian. Available from: http:// mg.co.za/article/2014-04-01-sa-holds-highest-number-ofnew-hiv-infections-worldwide-survey/. 
National Treasury. (2007). The VAT treatment of merit goods and services. Available from: http://www.treasury.gov.za/ publications/other/VAT\%20Merit\%20goods\%20Final\% 20Report\%20\%20-\%2015\%200ct\%202007.pdf.

OECD. (2011). Health at a glance 2011: OECD indicators. OECD Publishing. Available from: http://dx.doi.org/10.1787/health glance-2011-en.

Republic of South Africa. (1997). Medicines and Related Substances Amendment Act (Act 90 of 1997). Available from: http://www. gov.za/sites/www.gov.za/files/a90-97.pdf.

Republic of South Africa. (2015). Medicines and Related Substances Act 101 of 1965: Regulations relating to a transparent pricing system for medicines and scheduled substances: Dispensing fee for pharmacists. Government Gazette No 38566. Available from: http://www.gov.za/sites/www.gov.za/files/38566_gon211.pdf.

Schneider, H., Blaaw, D., Dartnall, E., Coetzee, D. J., \& Ballard, R. C. (2001). STD care in the South African private health sector. SAMJ, 91(2; Part 1), 151-156.
South African Medicine Price Registry. (2010). Database of medicine prices 10 November 2015. Available from: http://www.mpr.gov. $\mathrm{za} /$.

Southern African HIV Clinicians Society. (2013). Fixed-dose combination for adults accessing antiretroviral therapy. S Afr J HIV Med, 14(1), 41-43.

Southern African HIV Clinicians Society. (2014). Adult antiretroviral therapy guidelines 2014. S Afr J HIV Med, 15(4), 121-143.

The African Executive. (2005). VAT and import duties on medicines. Available from: http://www.africanexecutive.com/modules/ magazine/articles.php?article $=81$.

World Health Organization. (2010). Antiretroviral therapy for HIV infection in adults and adolescents: Recommendations for a public health approach-2010 revision. 